\title{
Preoperative geriatric nutritional risk index is a useful prognostic indicator in elderly patients with gastric cancer
}

\author{
Noriyuki Hirahara ${ }^{1}$, Takeshi Matsubara ${ }^{1}$, Yusuke Fujii ${ }^{1}$, Shunsuke Kaji ${ }^{1}$, Ryoji \\ Hyakudomi $^{1}$, Tetsu Yamamoto ${ }^{1}$, Yuki Uchida ${ }^{1}$, Yoshiko Miyazaki ${ }^{1}$, Kazunari Ishitobi ${ }^{1}$, \\ Yasunari Kawabata ${ }^{1}$ and Yoshitsugu Tajima ${ }^{1}$ \\ ${ }^{1}$ Department of Digestive and General Surgery, Shimane University Faculty of Medicine, Izumo, Shimane, Japan \\ Correspondence to: Noriyuki Hirahara, email: norinorihirahara@yahoo.co.jp \\ Keywords: geriatric nutritional risk index; overall survival; cancer-specific survival; gastric cancer; elderly patients \\ Received: April 20, $2020 \quad$ Accepted: May 25, $2020 \quad$ Published: June 16, 2020
}

Copyright: Hirahara et al. This is an open-access article distributed under the terms of the Creative Commons Attribution License 3.0 (CC BY 3.0), which permits unrestricted use, distribution, and reproduction in any medium, provided the original author and source are credited.

\section{ABSTRACT}

Background: The geriatric nutritional risk index (GNRI) was developed to evaluate the prognosis in elderly hospitalized patients at risk of malnutrition and related morbidity and mortality. This study aimed to evaluate the relationship between preoperative GNRI and long-term outcomes in elderly gastric cancer patients.

Materials and Methods: We retrospectively reviewed 297 consecutive patients aged $\geq 65$ years who underwent laparoscopic gastrectomy with $R 0$ resection and evaluated their overall survival (OS) and cancer-specific survival (CSS).

Results: In the univariate analyses, OS was significantly associated with the American Society of Anesthesiologists Physical Status (ASA-PS), tumor size, tumor differentiation, pathological stage, carcinoembryonic antigen (CEA), C-reactive protein, postoperative complications, and GNRI, whereas in the univariate analyses of CSS, ASA-PS, tumor size, tumor differentiation, pathological stage, CEA, postoperative adjuvant chemotherapy, and GNRI were significantly associated with poor prognosis. In the multivariate analysis, ASA-PS, tumor differentiation, pathological stage, and GNRI were significant independent prognostic factors of OS, whereas ASA-PS, pathological stage, and CEA were significant independent prognostic factors of CSS.

Conclusions: GNRI is significantly associated with OS and CSS in elderly gastric cancer patients and is an independent predictor of OS. It is a simple, cost-effective, and promising nutritional index for predicting os in elderly patients.

\section{INTRODUCTION}

The tumor-node-metastasis (TNM) staging has been the global standard for estimating cancer cell dissemination [1]. Nonetheless, TNM classification alone is not sufficient in predicting cancer outcomes because various factors, including tumor characteristics, systemic inflammation, and nutritional status, are involved in tumor progression [2, 3].

The impact of the nutritional status on the outcome of cancer patients has been intensively studied in recent years, and several assessment tools have been proposed for nutritional screening [4]. However, the usefulness of these tools has not been fully evaluated in elderly patients. The geriatric nutritional risk index (GNRI) was developed as a simple and objective nutritional assessment tool for hospitalized elderly patients (aged $\geq 65$ years, according to World Health Organization definition of elderly; https://www.who.int/) based on their body weight and serum albumin level [5]. Albumin is affected by agerelated changes such as hydration and hepatic and renal dysfunction [6-8]. In addition, body weight appears to be a good indicator of both the severity of systemic illness and the amount of protein-calorie stores [9, 10]. We, therefore, believe that the GNRI accurately reflects the nutritional status of elderly cancer patients who are at risk of malnutrition because of their physiological frailty and vulnerability.

The principal aim of this study was to evaluate the prognostic significance of the preoperative GNRI for estimating the postoperative outcomes of elderly gastric cancer patients. 


\section{RESULTS}

\section{GNRI and clinicopathological features}

The relationship between the GNRI values and the clinicopathological characteristics of the 297 patients enrolled in this study is summarized in Table 1. Based on the GNRI cutoff value for overall survival (OS), 97 (32.7\%) and $200(67.3 \%)$ patients were classified as having a low or high GNRI, respectively. There was a significant association between the GNRI and clinicopathological factors such as age $(p<0.001)$, body mass index (BMI) $(p<0.001)$, American Society of Anesthesiologists physical status (ASA-PS) $(p=0.014)$, red blood cell (RBC) count $(p<0.001)$, albumin $(p<0.001)$, C-reactive protein (CRP) $(p<0.001)$, tumor size $(p<0.001)$, tumor differentiation $(p=0.021)$, depth of tumor $(p<0.001)$, pathological stage $(p<0.001)$, and intraoperative blood loss $(p=0.048)$.

Based on the GNRI cutoff value for cancerspecific survival (CSS), 66 (22.2\%) and 231 patients (77.8\%) were classified as having a low or high GNRI, respectively. GNRI values were significantly associated with age $(p<0.001)$, BMI $(p<0.001)$, $\mathrm{RBC}(p<0.001)$, albumin $(p<0.001)$, CRP $(p<0.001)$, tumor size $(p<0.001)$, operative procedure $(p=0.043)$, depth of tumor $(p<0.001)$, pathological stage $(p<0.001)$, and intraoperative blood loss $(p=0.029)$.

Analysis based on the GNRI cutoff value for OS and CSS showed no causal relationship between GNRI values and postoperative complication rates.

\section{Cox regression analysis of OS}

In univariate analyses, OS was found to be significantly associated with ASA-PS $(p<0.001)$, tumor size $(p=0.018)$, tumor differentiation $(p<0.001)$, pathological stage $(p<0.001)$, carcinoembryonic antigen (CEA) $(p=0.005)$, CRP $(p=0.030)$, postoperative complications $(p=0.002)$, and GNRI $(p<0.001)$. Multivariate analysis revealed that ASA-PS (hazard ratio [HR]: 3.755; 95\% confidence interval [CI]: 2.130-6.619; $p<0.001$ ), tumor differentiation (HR: 1.798 ; 95\% CI: $1.132-2.857 ; p=0.013$ ), pathological stage (HR: 2.028; 95\% CI: $1.176-3.498 ; p=0.011$ ), and GNRI (HR: 2.350; 95\% CI: $1.436-3.847 ; p<0.001)$ were significant independent prognostic factors of OS (Table 2).

\section{Cox regression analysis of CSS}

The univariate analyses identified that CSS was significantly associated with ASA-PS $(p=0.014)$, tumor size $(p=0.001)$, tumor differentiation $(p=0.012)$, pathological stage $(p<0.001)$, CEA $(p=0.002)$, postoperative adjuvant chemotherapy $(p<0.001)$, and GNRI $(p=0.006)$. The ASA-PS (HR: $3.034 ; 95 \%$ CI: $1.272-7.234 ; p=0.012$ ), pathological stage (HR: 4.178;
95\% CI: $1.714-10.183 ; p=0.002$ ), and CEA (HR: $1.995 ; 95 \% \mathrm{CI} ; 1.016-3.914 ; p=0.045)$ were significant independent prognostic factors of CSS in the multivariate analysis. However, the GNRI was not confirmed to be an independent prognostic factor for CSS (Table 3).

\section{Postoperative OS analysis stratified by the GNRI}

Kaplan-Meier analysis and the log-rank test demonstrated that patients with a low GNRI had a significantly worse prognosis in terms of OS than those with a high GNRI $(p<0.001)$. The 5 -year OS rates for patients with low and high GNRI values were $52.2 \%$ and $78.9 \%$, respectively (Figure 1).

In the stratified analysis according to pTNM stage, patients with low GNRI only in pTNM stage I had a significantly worse OS compared with patients with normal GNRI $(p<0.001)$; however, no significant differences were found among gastric cancer patients with pTNM stage II and III (Figure 2A-2C).

\section{Postoperative CSS analysis stratified by the GNRI}

Kaplan-Meier analysis and the log-rank test revealed a worse prognosis in terms of CSS in patients with a low GNRI than those with a high GNRI $(p=0.004)$. The 5-year CSS rates for patients with low and high GNRI values were $73.2 \%$ and $88.4 \%$, respectively (Figure 3 ).

The stratified analysis according to pTNM stage showed that patients with low GNRI had significantly worse CSS than patients with normal GNRI only in pTNM stage I $(p=0.006)$; however, there were no significant differences among gastric cancer patients with pTNM stage II and III (Figure 4A-4C).

\section{DISCUSSION}

Malnutrition is a very common problem among the elderly. It is caused by age-related physical, psychological, or physiological changes [11], leading to diminished quality of life, performance status, immune function, and resistance to infections $[12,13]$. Furthermore, malnutrition is particularly common in patients with gastrointestinal cancer because the disease mechanically inhibits the oral intake of food and/or directly impairs digestion either through local or systemic effects.

Several nutritional assessment tools have been developed to predict the prognosis of cancer patients, including the Glasgow Prognostic Score (GPS), the Controlling Nutritional Status (CONUT) score, and the Prognostic Nutritional Index (PNI) [14-16]. However, the clinical application of these tools in elderly cancer patients is limited because of the lack of consensus regarding their usefulness. The GNRI was originally developed as an objective and simple nutritional screening tool to 
Table 1: Relationships between GNRI and clinicopathological features in all elderly patients with gastric cancer

\begin{tabular}{|c|c|c|c|c|c|c|c|}
\hline \multirow{3}{*}{ Characteristics } & \multirow{3}{*}{$\begin{array}{c}\text { Number of } \\
\text { patients }\end{array}$} & \multicolumn{3}{|c|}{ GNRI (based on OS) } & \multicolumn{3}{|c|}{ GNRI (based on CSS) } \\
\hline & & $<94.8$ & $\geq 94.8$ & & $<90.9$ & $\geq 90.9$ & \\
\hline & & $(n=97)$ & $(n=200)$ & $p$ value & $(n=66)$ & $(n=231)$ & $p$ value \\
\hline Age (years old) & & $79(65-91)$ & $74(65-89)$ & $<0.001$ & $79(65-91)$ & $75(65-89)$ & $<0.001$ \\
\hline Gender & & & & 0.601 & & & 0.441 \\
\hline Male & 205 & 65 & 140 & & 43 & 162 & \\
\hline Female & 92 & 32 & 60 & & 23 & 69 & \\
\hline BMI & & $20.8(14.7-30.5)$ & $22.9(16.5-40.4)$ & $<0.001$ & $20.1(14.7-30.5)$ & $22.8(16.5-40.4)$ & $<0.001$ \\
\hline ASA-PS & & & & 0.014 & & & 0.069 \\
\hline 1 & 8 & 0 & 8 & & 0 & 8 & \\
\hline 2 & 256 & 80 & 176 & & 54 & 202 & \\
\hline$\geq 3$ & 33 & 17 & 16 & & 12 & 21 & \\
\hline WBC $(\mu \mathrm{l})$ & & $5450(1830-13700)$ & $5695(510-9830)$ & 0.260 & $5520(1830-13700)$ & $5680(510-10300)$ & 0.833 \\
\hline $\mathrm{RBC}\left(\times 10^{4} \mu \mathrm{l}\right)$ & & $365(142-570)$ & $435(203-579)$ & $<0.001$ & $367(142-570)$ & $427(203-579)$ & $<0.001$ \\
\hline Albumin (g/dl) & & $3.4(1.1-4.0)$ & $4.2(3.6-5.0)$ & $<0.001$ & $3.2(1.1-3.9)$ & $4.1(3.4-5.0)$ & $<0.001$ \\
\hline CRP (mg/l) & & $0.16(0.01-11.1)$ & $0.07(0.01-7.09)$ & $<0.001$ & $0.24(0.01-11.1)$ & $0.07(0.01-7.09)$ & $<0.001$ \\
\hline Location of tumor & & & & 0.119 & & & 0.510 \\
\hline EGJ & 11 & 1 & 10 & & 1 & 10 & \\
\hline $\mathrm{U}$ & 53 & 22 & 31 & & 15 & 38 & \\
\hline M & 122 & 35 & 87 & & 26 & 96 & \\
\hline $\mathrm{L}$ & 111 & 39 & 72 & & 24 & 87 & \\
\hline Tumor size (mm) & & $58(7-180)$ & $36(3-176)$ & $<0.001$ & $60(7-170)$ & $40(3-180)$ & $<0.001$ \\
\hline Procedure & & & & 0.118 & & & 0.043 \\
\hline LTG & 63 & 27 & 36 & & 21 & 42 & \\
\hline LPG & 29 & 7 & 22 & & 4 & 25 & \\
\hline L(A)DG & 205 & 63 & 142 & & 41 & 164 & \\
\hline Tumor differentiation & & & & 0.021 & & & 0.101 \\
\hline Well & 65 & 12 & 53 & & 9 & 56 & \\
\hline Moderate & 120 & 43 & 77 & & 26 & 94 & \\
\hline Poor & 112 & 42 & 70 & & 31 & 81 & \\
\hline Depth of tumor & & & & $<0.001$ & & & $<0.001$ \\
\hline T1a-1b & 145 & 31 & 114 & & 19 & 126 & \\
\hline 2 & 44 & 12 & 32 & & 7 & 37 & \\
\hline 3 & 44 & 24 & 20 & & 17 & 27 & \\
\hline $4 a-4 b$ & 64 & 30 & 34 & & 23 & 41 & \\
\hline $\begin{array}{l}\text { Lymph node } \\
\text { metastasis }\end{array}$ & & & & 0.145 & & & 0.158 \\
\hline N0 & 192 & 57 & 135 & & 38 & 154 & \\
\hline N1 & 38 & 11 & 27 & & 8 & 30 & \\
\hline $\mathrm{N} 2$ & 35 & 17 & 18 & & 13 & 22 & \\
\hline N3 & 32 & 12 & 20 & & 7 & 25 & \\
\hline Pathological stage & & & & $<0.001$ & & & $<0.001$ \\
\hline $1 a-1 b$ & 171 & 38 & 133 & & 24 & 147 & \\
\hline $2 a-2 b$ & 53 & 26 & 27 & & 18 & 35 & \\
\hline $3 a-3 c$ & 73 & 33 & 40 & & 24 & 49 & \\
\hline Operation time (min) & & $390(204-911)$ & $409(70-808)$ & 0.396 & $392(204-911)$ & $406(70-808)$ & 0.643 \\
\hline $\begin{array}{l}\text { Intraoperative blood } \\
\text { loss }\end{array}$ & & $100(0-1600)$ & $45(0-4070)$ & 0.048 & $125(0-1600)$ & $50(0-4070)$ & 0.029 \\
\hline CEA (ng/ml) & & $3.4(0.8-163.3)$ & $3.4(0.7-161.1)$ & 0.314 & $3.7(0.8-163.3)$ & $3.3(0.7-161.1)$ & 0.078 \\
\hline $\begin{array}{l}\text { Postoperative } \\
\text { complications }\end{array}$ & & & & 0.292 & & & 0.387 \\
\hline
\end{tabular}




\begin{tabular}{|c|c|c|c|c|c|c|c|c|c|}
\hline absent & 202 & 62 & \multicolumn{2}{|c|}{140} & & 42 & & 160 & \multirow{5}{*}{0.888} \\
\hline present & 95 & 35 & \multicolumn{2}{|c|}{60} & & 24 & & 71 & \\
\hline $\begin{array}{l}\text { Adjuvant } \\
\text { chemotherapy }\end{array}$ & & & & & 0.737 & & & & \\
\hline Yes & 79 & 27 & \multicolumn{2}{|c|}{52} & & 18 & \multicolumn{2}{|r|}{61} & \\
\hline No & 218 & 70 & \multicolumn{2}{|c|}{148} & & 48 & \multicolumn{2}{|r|}{170} & \\
\hline \multicolumn{10}{|c|}{$\begin{array}{l}\text { Abbreviations: OS: overall survival, CSS: cancer-specific survival, GNRI: geriatric nutritional risk index, BMI: body mass index, ASA-PS: American Society of Anesthesiologists } \\
\text { physical status, WBS: white blood cell, RBC: red blood cell, CRP: C-reactive protein, EGJ: esophagogastric junction, U: upper part, M: middle part, L: lower part, CEA: } \\
\text { carcinoembryonic antigen, LTG: laparoscopic total gastrectomy, LPG: laparoscopic proximal gastrectomy, L(A)Dg: laparoscopic (assisted) distal gastrectomy. }\end{array}$} \\
\hline \multirow{2}{*}{ Variables } & \multirow{2}{*}{\multicolumn{2}{|c|}{$\begin{array}{l}\text { Category or } \\
\text { characteristics }\end{array}$}} & \multirow{2}{*}{$\begin{array}{l}\text { Patients } \\
(n=297)\end{array}$} & \multicolumn{3}{|c|}{ Univariate analysis } & \multicolumn{3}{|c|}{ Multivariate analysis } \\
\hline & & & & HR & $95 \%$ CI & $p$ value & HR & $95 \%$ CI & $p$ value \\
\hline Gender & & (female/male) & $92 / 205$ & 1.158 & $0.718-1.866$ & 0.547 & & & \\
\hline ASA-PS & & $(<3 / \geq 3)$ & $264 / 33$ & 3.937 & $2.306-6.721$ & $<0.001$ & 3.755 & $2.130-6.619$ & $<0.001$ \\
\hline BMI & & $(\geq 18.5 /<18.5)$ & $269 / 28$ & 1.652 & $0.874-3.122$ & 0.122 & & & \\
\hline Tumor size & & $(<5 / \geq 5)$ & $163 / 134$ & 1.706 & $1.097-2.653$ & 0.018 & 1.123 & $0.641-1.970$ & 0.685 \\
\hline Differentiation & & (well \& mod/poor) & $184 / 113$ & 2.132 & $1.375-3.305$ & $<0.001$ & 1.798 & $1.132-2.857$ & 0.013 \\
\hline Pathological stage & & $(1,2 / 3)$ & $224 / 73$ & 2.720 & $1.751-4.225$ & $<0.001$ & 2.028 & $1.176-3.498$ & 0.011 \\
\hline CEA & & $(<5.0 / \geq 5.0)$ & $225 / 72$ & 1.936 & $1.222-3.066$ & 0.005 & 1.593 & $0.993-2.557$ & 0.054 \\
\hline CRP & & $(\leqq 0.5 />0.5)$ & $248 / 49$ & 1.750 & $1.055-2.904$ & 0.030 & 1.170 & $0.656-2.088$ & 0.595 \\
\hline GNRI & & $(>94.8 /<94.8)$ & $200 / 97$ & 2.470 & $1.596-3.823$ & $<0.001$ & 2.350 & $1.436-3.847$ & $<0.001$ \\
\hline Complications & & (absent/present) & $202 / 95$ & 1.985 & $1.275-3.089$ & 0.002 & 1.532 & $0.961-2.440$ & 0.073 \\
\hline Intraope. blood loss & & $(<50 / \geq 50)$ & $(163 / 134)$ & 1.615 & $0.998-2.615$ & 0.051 & & & \\
\hline Adjuvant Chemo & & (no/yes) & $218 / 79$ & 1.544 & $0.979-2.434$ & 0.062 & & & \\
\hline
\end{tabular}

Abbreviations: HR: hazard ratio, CI: confidence interval, ASA-PS: American Society of Anesthesiologists physical status, BMI: body mass index, mod: moderately, poor: poorly, CEA: carcinoembryonic antigen, CRP: C-reactive protein, GNRI: geriatric nutritional risk index, Complications: postoperative complications, Intraope. blood loss: intraoperative blood loss, Adjuvant chemo: adjuvant chemotherapy.

evaluate the nutrition-related risks of hospitalized elderly patients. Patients were divided into four groups based on the GNRI values: high risk (GNRI $<82$ ), moderate risk (GNRI 82-92), low risk (GNRI 92-98), and normal level (GNRI > 98) [5]. However, in this study, the longterm outcome of gastric cancer patients was examined regardless of their hospitalization status in order to create a cutoff value using receiver operating characteristic (ROC) analysis. Patients have also been classified into the low- and high-GNRI groups, and an association between low GNRI and mortality in elderly patients with chronic obstructive pulmonary disease, chronic kidney disease, or chronic heart failure was recently reported [17-20]. However, the use of the GNRI for cancer patients is not fully standardized, and its availability is limited because of the small number of studies reported.

In other contexts, GNRI has been reported as a useful tool for screening nutritional status, which is commonly determined using albumin and body weight loss [5]. Albumin stabilizes cell growth and DNA replication, participates in a variety of biochemical changes, protects against tumorigenesis, and maintains sex hormone homeostasis. Generally, hypoalbuminemia is commonly recognized in elderly populations caused by poor dietary intake, protein loss, or catabolic metabolism; therefore, albumin can reflect the inflammation and immune status of cancer cells [21, 22]. Likewise, most elderly patients are malnourished because of poor dietary intake, protein loss, or catabolic metabolism. Malnutrition is a complex state that is often related to functional impairment, disability, poor health, and aging, resulting in protein and energy deficiency, energy collapse, and impaired immunity. BMI, which considers the body weight and height, is also commonly used to assess an individual's nutritional status [23, 24]. Therefore, GNRI, which is based on the combination of albumin and BMI, is a more accurate predictor of nutritional status than either of these parameters alone. As expected, a low GNRI adversely affected OS after laparoscopic gastrectomy in gastric cancer patients aged 65 or older in this study. However, it did not affect CSS. Although the mechanisms by which GNRI affects only provisional OS and not CSS is difficult to clarify, the possible reasons could be the increase in oral intake disorders that tends to occur with aging results in hypoalbuminemia and malnutrition [25]; cancer promotes inflammation and impairs nutrient absorption by increasing the production of catabolic cytokines, which accelerate malnutrition [26, 27]; and aging itself is associated with a systemic chronic lowgrade inflammation; hence, a vicious cycle of malnutrition and inflammation occurs in gastric cancer patients, especially in the elderly [28-30]. We, therefore, believe 
Table 3: Univariate and multivariate analyses of clinicopathological factors for cancer-specific survival

\begin{tabular}{|c|c|c|c|c|c|c|c|c|}
\hline \multirow{2}{*}{ Variables } & \multirow{2}{*}{ Category or characteristics } & \multirow{2}{*}{$\begin{array}{l}\text { Patients } \\
(n=297)\end{array}$} & \multicolumn{3}{|c|}{ Univariate analysis } & \multicolumn{3}{|c|}{ Multivariate analysis } \\
\hline & & & HR & $95 \% \mathrm{CI}$ & $p$ value & HR & $95 \% \mathrm{CI}$ & $p$ value \\
\hline Gender & (female/male) & $92 / 205$ & 1.433 & $0.673-3.048$ & 0.351 & & & \\
\hline ASA & $(<3 / \geq 3)$ & $264 / 33$ & 2.839 & $1.237-6.519$ & 0.014 & 3.034 & $1.272-7.234$ & 0.012 \\
\hline BMI & $(\geq 18.5 /<18.5)$ & $269 / 28$ & 1.381 & $0.487-3.913$ & 0.544 & & & \\
\hline Tumor size & $(<5 / \geq 5)$ & $163 / 134$ & 3.339 & $1.605-6.946$ & 0.001 & 1.366 & $0.567-3.291$ & 0.487 \\
\hline Differentiation & (well \& mod/poor) & $184 / 113$ & 2.335 & $1.203-4.530$ & 0.012 & 1.264 & $0.616-2.594$ & 0.523 \\
\hline Pathological stage & $(1,2 / 3)$ & $224 / 73$ & 7.720 & $3.796-15.699$ & $<0.001$ & 4.178 & $1.714-10.183$ & 0.002 \\
\hline CEA & $(<5.0 / \geq 5.0)$ & $225 / 72$ & 2.773 & $1.436-5.357$ & 0.002 & 1.995 & $1.016-3.914$ & 0.045 \\
\hline CRP & $(\leqq 0.5 />0.5)$ & $248 / 49$ & 1.566 & $0.712-3.444$ & 0.264 & & & \\
\hline GNRI & $(>90.9 /<90.9)$ & $231 / 66$ & 2.578 & $1.318-5.043$ & 0.006 & 1.754 & $0.849-3.625$ & 0.129 \\
\hline Complications & (absent/present) & $202 / 95$ & 1.706 & $0.872-3.339$ & 0.119 & & & \\
\hline Intraope. blood loss & $(<50 / \geq 50)$ & $(163 / 134)$ & 1.989 & $0.955-4.141$ & 0.066 & & & \\
\hline Adjuvant chemo & (no/yes) & $218 / 79$ & 4.190 & $2.142-8.198$ & $<0.001$ & 1.761 & $0.795-3.900$ & 0.163 \\
\hline
\end{tabular}

Abbreviations: HR: hazard ratio, CI: confidence interval, ASA-PS: American Society of Anesthesiologists physical status, BMI: body mass index, mod: moderately, poor: poorly, CEA: carcinoembryonic antigen, CRP: C-reactive protein, GNRI: geriatric nutritional risk index, Complications: postoperative complications, Intraope. blood loss; intraoperative blood loss, Adjuvant chemo: adjuvant chemotherapy.

that the GNRI can accurately predict OS because it reflects the integrated nutritional status associated with cancer progression and other age-related catabolic reactions.

In the future, the potential cancer-specific predictability of other prognostic nutritional scores such as the GPS, CONUT, and PNI, which consider albumin and other immune-nutritional factors, should be validated. Recently, several studies have indicated that a systemic inflammatory response may be associated with poor outcome in patients with advanced cancer. In particular, the GPS, an inflammation-based prognostic score that includes CRP and albumin, is one of the most useful scoring systems for prognosticating patients with various advanced cancers [31, 32]. CONUT, which is calculated using albumin, total lymphocyte, and total cholesterol, comprehensively reflects the balance between host inflammatory and immune responses because cholesterol is used as a parameter of caloric storage and lymphocyte is used as an indicator of immune status $[16,33]$. Additionally, PNI, which is based on lymphocyte and albumin, was originally reported as a nutritional assessment tool for predicting the risk of operative morbidity after gastrointestinal surgery. Currently, PNI can be considered a good indicator of prognosis and the

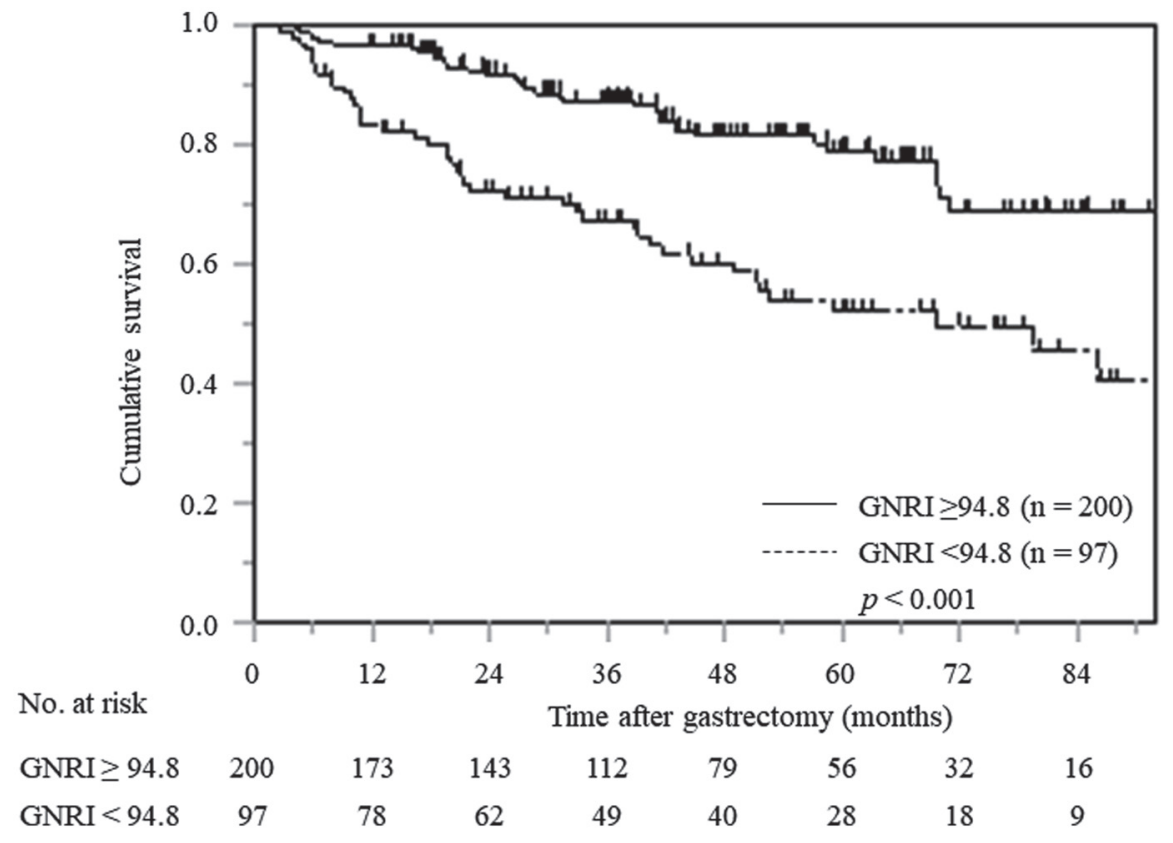

Figure 1: Kaplan-Meier curves of postoperative OS based on GNRI in all elderly gastric cancer patients. 
A

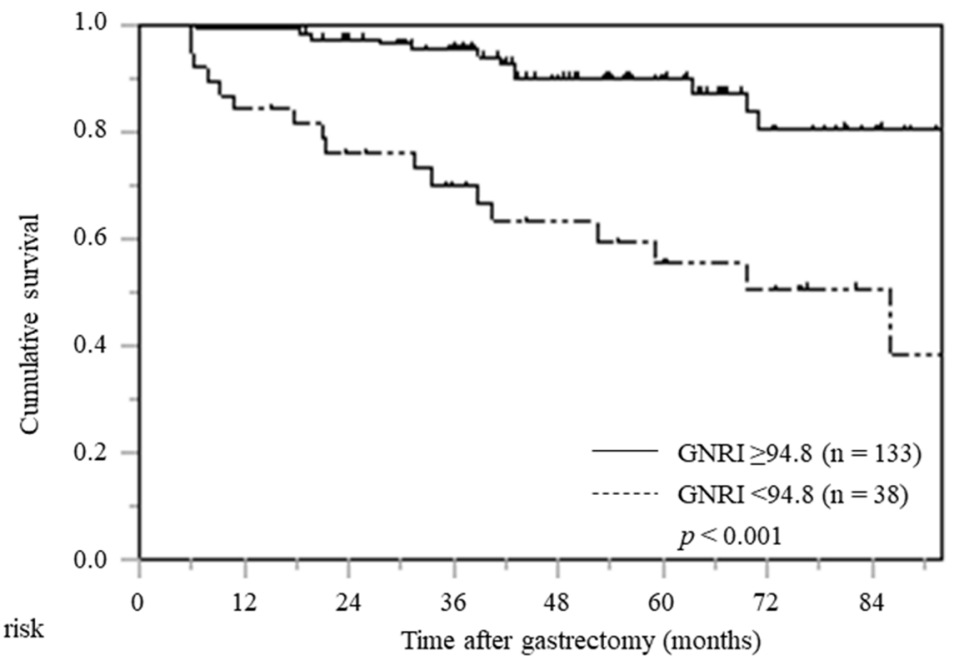

No. at risk

$\begin{array}{ccccccccc}\text { GNRI } \geq 94.8 & 133 & 127 & 103 & 88 & 60 & 43 & 24 & 15 \\ \text { GNRI }<94.8 & 38 & 33 & 28 & 22 & 18 & 14 & 12 & 5 \\ \text { B } & & & \end{array}$

B

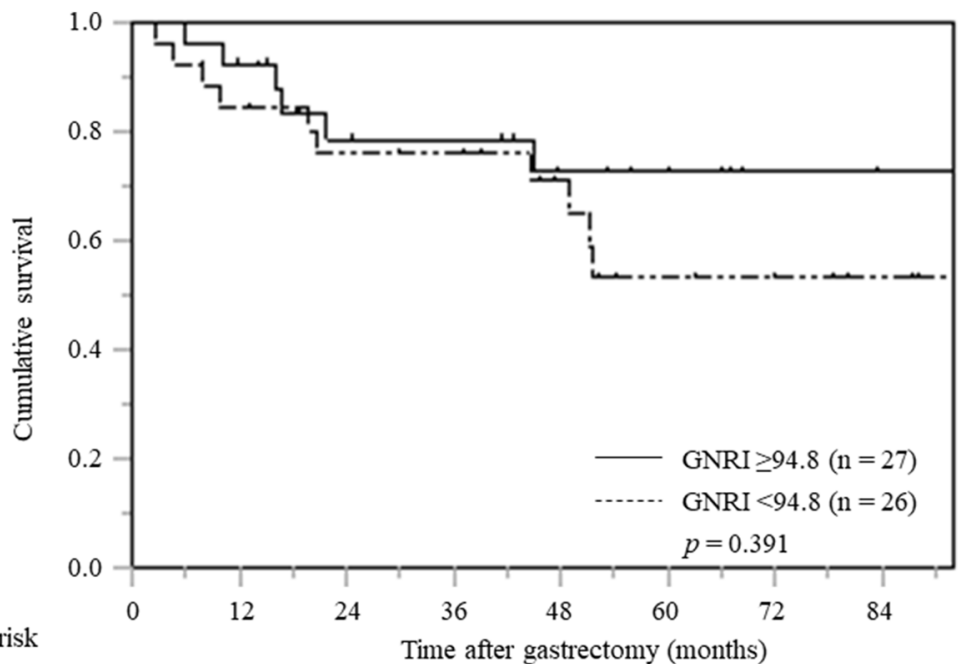

No. at risk

Time after gastrectomy (months)

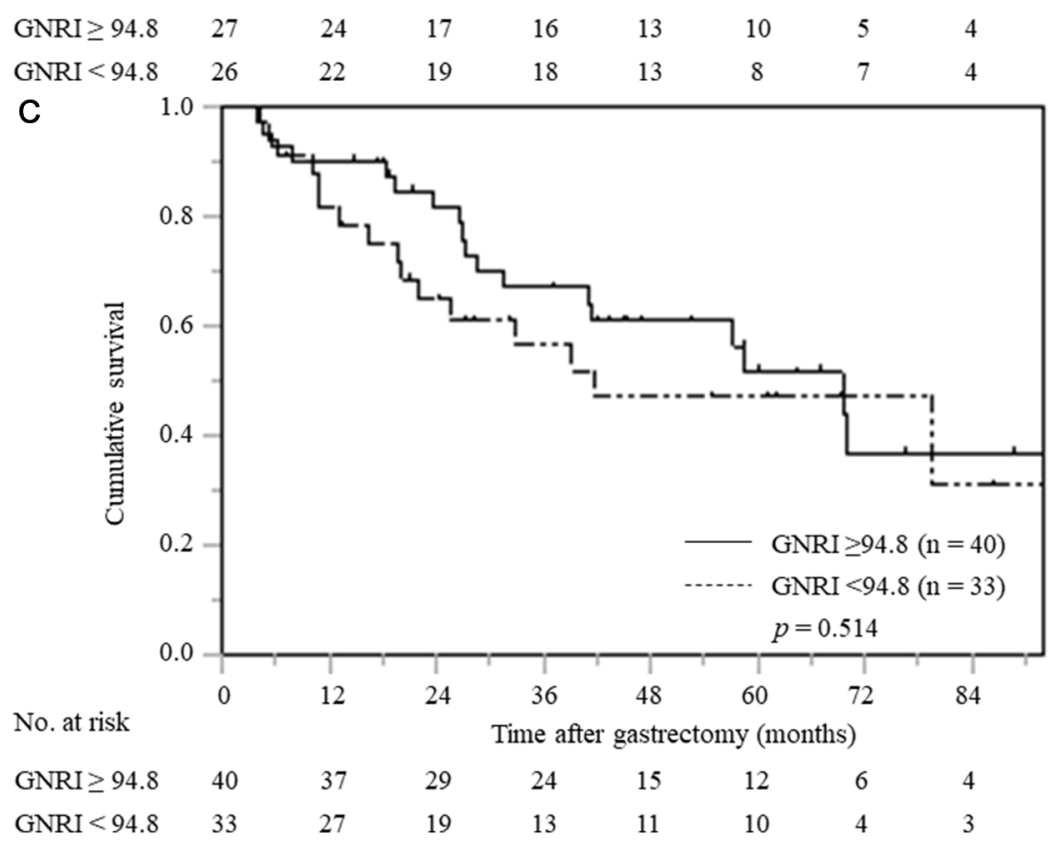

Figure 2: Overall survival curves based on GNRI according to pTNM stage. (A) pTNM stage I $(n=171)$, (B) pTNM stage II $(n=53)$, (C) pTNM stage III $(n=73)$. 
immune and nutritional status of patients with cancer $[34,35]$.

This study has some limitations that should be considered when interpreting the results. First, this study has a small sample size, which accounts for the lack of statistical power, and thus, we were unable to obtain sufficient information on preoperative comorbidities. To draw a better conclusion, a multicenter, large-scale study is needed to establish the role of GNRI as a prognostic predictor in patients with gastric cancer. Second, there are no consensual cutoff values for GNRI in predicting OS. The universal cutoff value should be verified in prospective and well-designed randomized controlled trials before it is adopted in routine practice. Third, the definition of elderly population is not consistent among researchers. Finally, GNRI has not been compared with other nutritional assessment tools; therefore, future prospective randomized studies are warranted to investigate the significance of preoperative nutritional intervention for improving surgical outcome in gastric cancer patients.

This study evaluated the association between preoperative GNRI and long-term outcomes in elderly gastric cancer patients. The GNRI, which was originally developed as an objective and simple nutritional screening tool to evaluate the nutrition-related risk index in elderly hospitalized patients, has been reported to be associated with mortality in elderly patients with chronic obstructive pulmonary disease, chronic kidney disease, and/or chronic heart failure. However, this is one of the few studies that assessed the use of GNRI for elderly patients with gastric cancer. In conclusion, GNRI proved to be a promising candidate not only for assessing the nutritional status of hospitalized elderly patients but also for predicting OS in elderly gastric cancer patients after laparoscopic gastrectomy because it reflects the integrated nutritional status associated with cancer progression and age-related catabolic reactions. When deciding a treatment strategy for cancer patients, tumor- and hostrelated factors should be considered. Recently, GNRI has been reported as an accurate tool to assess the risk of patients with chronic obstructive pulmonary disease, with cardiovascular disease, undergoing hemodialysis, and with chronic renal failure. In Japan, which has an aging society, individualized treatment strategy for gastric cancer is indispensable because there are many deaths caused by other diseases. Recently, sarcopenia has been reported to affect the incidence of adverse events with chemotherapy and the continuation of treatment, leading to worse prognosis. Sarcopenia, the age-related loss of skeletal muscle mass and strength, was identified based on cross-sectional computed tomography images at the L3 level [36]. However, GNRI can be easily calculated from routine laboratory data and physical measurements. The clinical significance of GNRI, as an indicator of OS, will be increasingly important in the future.

\section{MATERIALS AND METHODS}

\section{Patients}

We conducted a retrospective analysis of elderly patients with gastric cancer who underwent curative laparoscopic (assisted) gastrectomy at our institute

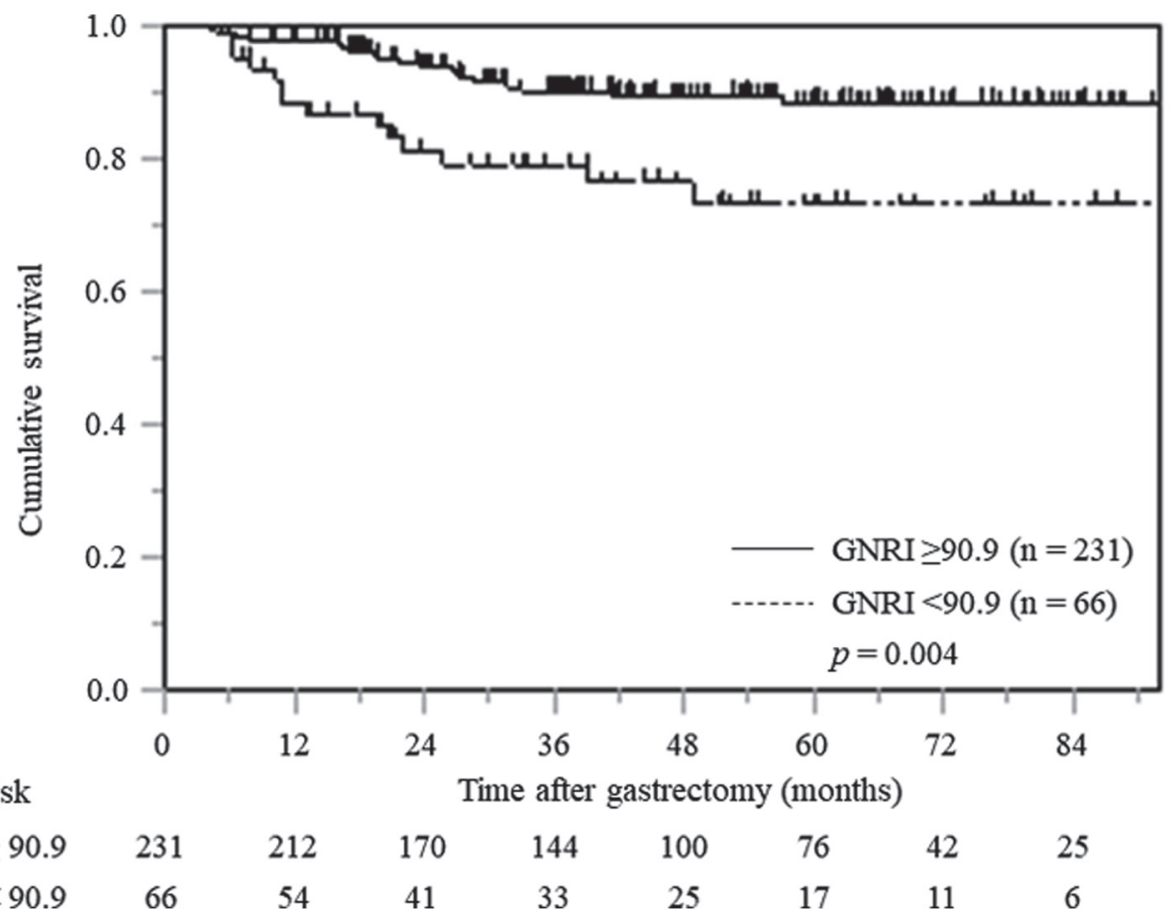

Figure 3: Kaplan-Meier curves of postoperative CSS based on GNRI in all gastric cancer patients. 
A

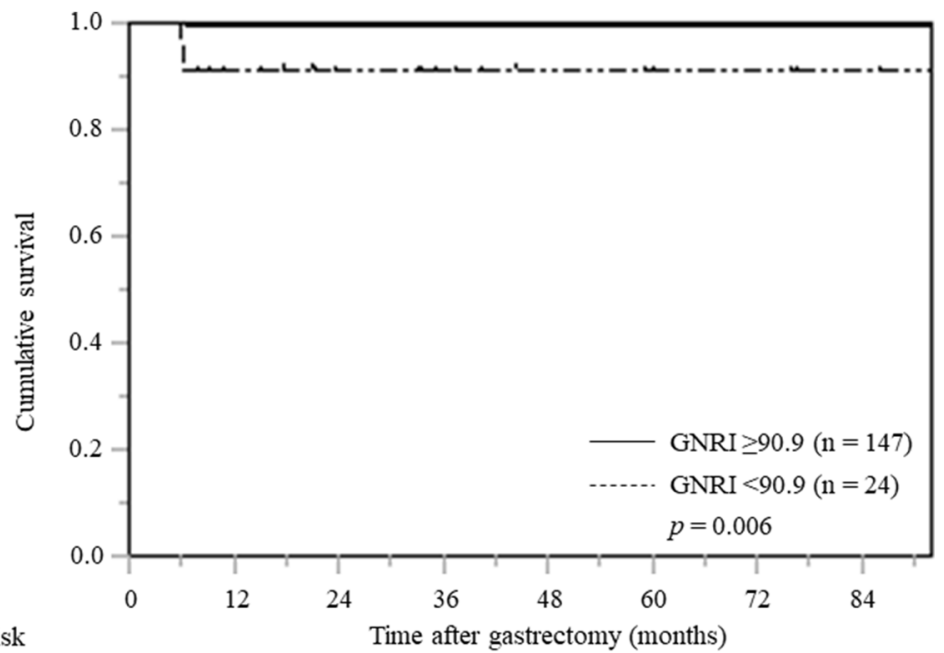

No. at risk

Time after gastrectomy (months)

$\begin{array}{ccccccccc}\text { GNRI } \geq 90.9 & 147 & 141 & 117 & 99 & 71 & 52 & 30 & 17 \\ \text { GNRI }<90.9 & 24 & 19 & 14 & 11 & 8 & 6 & 6 & 3\end{array}$

B

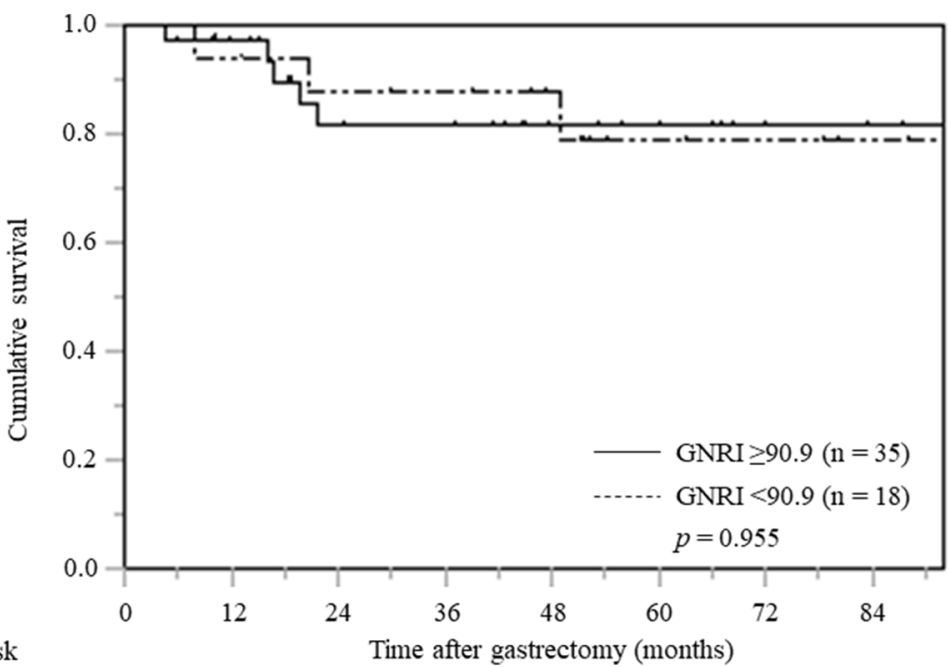

No. at risk Time after gastrectomy (months)

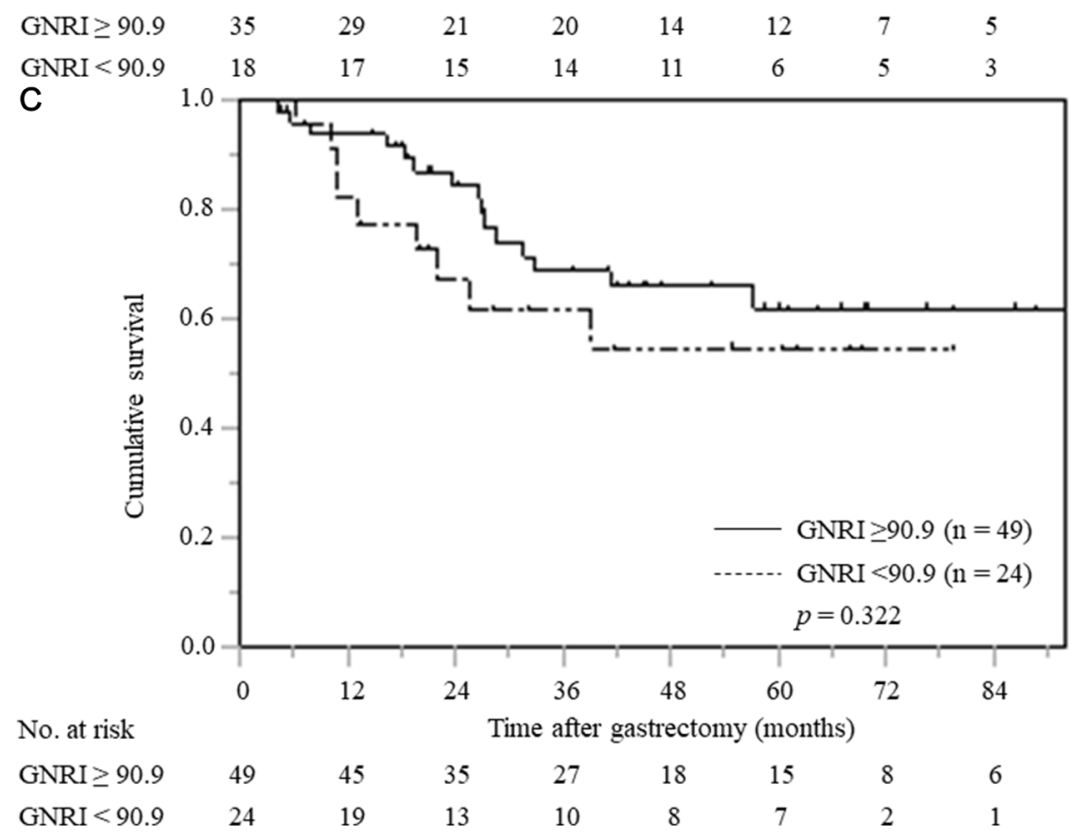

Figure 4: Cancer-specific survival curves based on GNRI according to pTNM stage. (A) pTNM stage I $(n=171)$, (B) pTNM stage II $(n=53),($ C) pTNM stage III $(n=73)$. 
between January 2010 and December 2017. The inclusion criteria were age $\geq 65$ years (according to the World Health Organization's definition of elderly; https://www. who.int/), histologically verified gastric adenocarcinoma, no distant metastasis, Eastern Cooperative Oncology Group performance status $\leq 2$, and curative gastrectomy. The exclusion criteria were remnant gastric cancer, T4b disease, emergency gastrectomy for bleeding or perforation, mortality related to surgery within 30 days, and coexisting hematological, inflammatory, or autoimmune disorders. Based on these inclusion and exclusion criteria, a total of 297 patients were enrolled in the study. Our study was approved by the Ethical Review Board of the Shimane University Faculty of Medicine, Shimane, Japan (authorization number: 4011).

\section{Outcome evaluation}

The median follow-up time was 36.0 months (range: 2.8-96.5 months) in all patients after gastrectomy.

The observation period started on the date of gastrectomy and ended on the date of death, last followup, or withdrawal of consent. OS and CSS were assessed based on the cause of death as determined from manual or
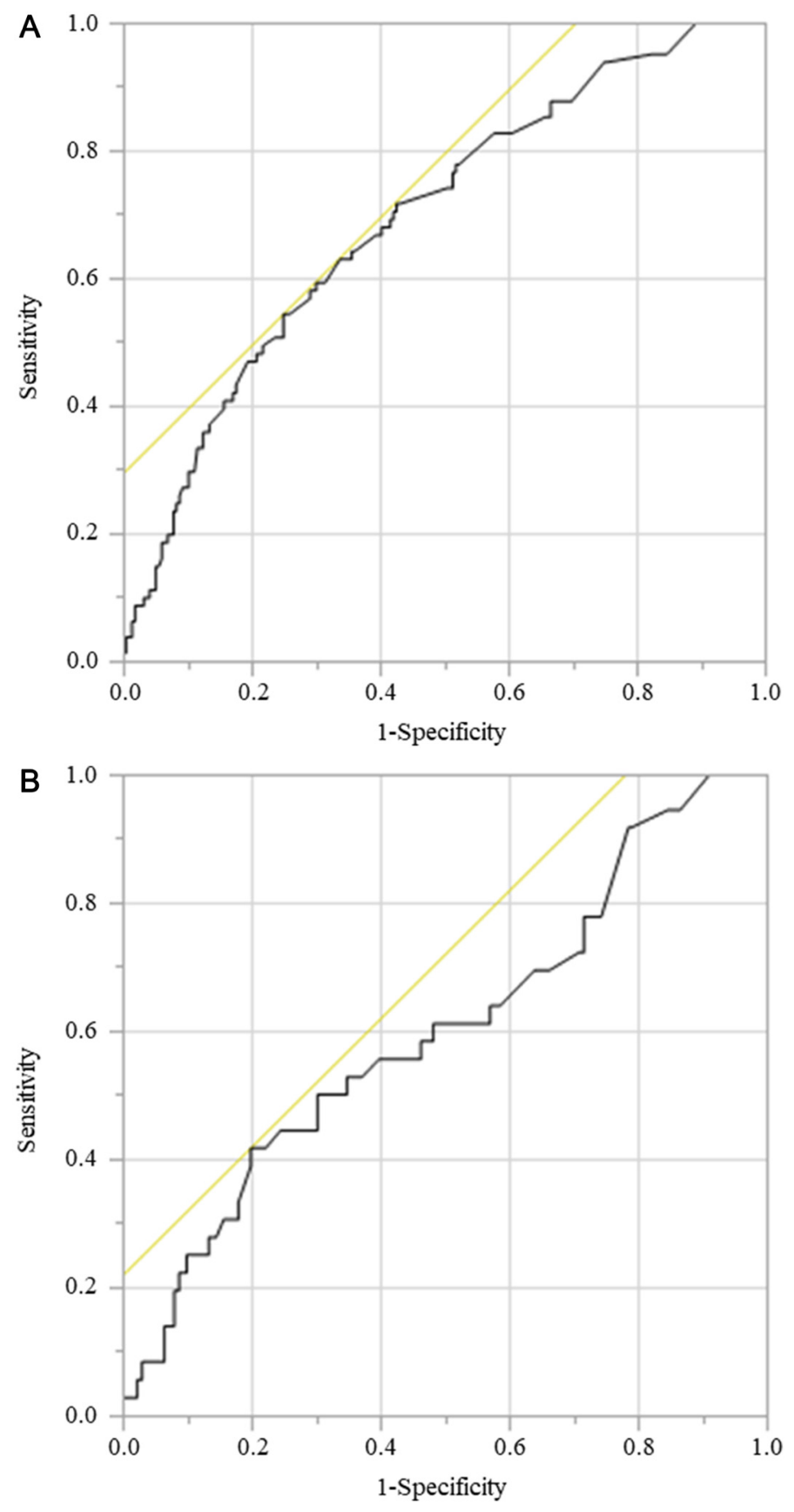

Figure 5: ROC for GNRI as a predictive factor for postoperative survival was plotted to verify the optimum cutoff value of GNRI. (A) overall survival, (B) cancer-specific survival. 
computerized records. OS was calculated using the period from the date of primary gastrectomy to the date of death from any cause or last follow-up. CSS was defined as the interval from the date of surgery to cancer-related death or withdrawal of consent.

The pathological stage was assigned in accordance with the TNM classification (7th edition) [1]. We categorized postoperative complications according to the Clavien-Dindo (CD) classification, and postoperative complications were defined as grade II or higher [37].

\section{GNRI calculation}

Preoperative laboratory data, including the GNRI, and physical measurements were obtained in each patient within 7 days prior to surgery.

The GNRI was developed by combining two nutritional indicators: albumin and actual weight compared with ideal body weight. The GNRI formula is as follows: GNRI $=[1.487 \times$ serum albumin $(\mathrm{g} / \mathrm{L})]+[41.7 \times$ actual/usual body weight) (kg)]. The formula for the ideal body weight is as follows: ideal body weight $(\mathrm{kg})=22 \times$ square of height $\left(\mathrm{m}^{2}\right)$ [5]. When the patient's actual BW is greater than the ideal $\mathrm{BW}$, the ratio of the actual BW to the ideal BW was 1 .

A ROC curve was generated to verify the optimal cutoff value of preoperative GNRI for predicting OS and CSS. The ability of GNRI to predict OS and CSS was evaluated using the area under the ROC curve (AUC) estimation method. The GNRI ranged from 54.4 to 117.6 , and the mean GNRI was 98.5. The median GNRI was 99.9. The optimal cutoff value for preoperative GNRI was set at 94.8 for OS (sensitivity, 54.3\%; specificity, $75.0 \%$; $\mathrm{AUC}=0.694$ ) and 90.9 for CSS (sensitivity, $41.7 \%$; specificity, $80.1 \%$; AUC $=0.599$ ). Patients were categorized as having a low or high GNRI based on the cutoff values (Figure 5A, 5B).

\section{Statistical analysis}

Comparisons were performed using the chi-square test or Student's $t$-test for categorical variables and the MannWhitney $U$ test for non-normally distributed continuous variables. The OS and CSS were calculated using the Kaplan-Meier method, and the differences between the survival curves were assessed by the log-rank test.

Univariate analyses were also performed to identify variables that were significantly associated with OS or CSS, and variables with a univariate $p$ value $<0.05$ were included in the multivariate analysis, for which a Cox proportional hazards model was used. JMP version 14 (SAS Institute, Cary, NC, USA) was used for the statistical analyses.

\section{Abbreviations}

ASA-PS: American Society of Anesthesiologists physical status; AUC: area under the curve; BMI: body mass index; CD: Clavien-Dindo; CEA: carcinoembryonic antigen; CONUT: Controlling Nutritional Status; CRP: C-reactive protein; CSS: cancer-specific survival; GNRI: geriatric nutritional risk index; GPS: Glasgow Prognostic Score; HR: hazard ratio; OS: overall survival; PNI: Prognostic Nutritional Index; RBC: red blood cell; ROC: receiver operating characteristic; TNM: tumor-nodemetastasis.

\section{Author contributions}

NH was the lead author and conceived this study. TM, YF, SK, and RH conducted this research. TY, YM, YU, KI, and YK collected the data, performed the analyses, and drafted the manuscript. YT reviewed the paper and the surgery technique. All authors read and approved the final manuscript.

\section{ACKNOWLEDGMENTS}

None.

\section{CONFLICTS OF INTEREST}

Authors have no conflicts of interest to declare.

\section{FUNDING}

This study received no external sources of funding.

\section{REFERENCES}

1. Sobin LH, Gospodarowicz MK, Wittekind C. TNM classification of malignant tumors. 7th ed. Oxford: Wiley. 2010 .

2. Schink K, Herrmann HJ, Schwappacher R, Meyer J, Orlemann T, Waldmann E, Wullich B, Kahlmeyer A, Fietkau R, Lubgan D, Beckmann MW, Hack C, Kemmler $\mathrm{W}$, et al. Effects of whole-body electromyostimulation combined with individualized nutritional support on body composition in patients with advanced cancer: a controlled pilot trial. BMC Cancer. 2018; 18:886. https:// doi.org/10.1186/s12885-018-4790-y. [PubMed]

3. Chen MJ, Wu IC, Chen YJ, Wang TE, Chang YF, Yang CL, Huang WC, Chang WK, Sheu BS, Wu MS, Lin JT, Chu $\mathrm{CH}$. Nutrition therapy in esophageal cancer-Consensus statement of the Gastroenterological Society of Taiwan. Dis Esophagus. 2018; 31. https://doi.org/10.1093/dote/doy016. [PubMed]

4. Sasaki H, Nagano S, Komiya S, Taniguchi N, Setoguchi T. Validation of Different Nutritional Assessment Tools in Predicting Prognosis of Patients with Soft Tissue SpindleCell Sarcomas. Nutrients. 2018; 10:765. https://doi. org/10.3390/nu10060765. [PubMed] 
5. Bouillanne O, Morineau G, Dupont C, Coulombel I, Vincent JP, Nicolis I, Benazeth S, Cynober L, Aussel C. Geriatric Nutritional Risk Index: A new index for evaluating at-risk elderly medical patients. Am J Clin Nutr. 2005; 82:777-83. https://doi.org/10.1093/ajen/82.4.777. [PubMed]

6. Hoppe K, Schwermer K, Kawka A, Klysz P, Baum E, Kaluzna M, Sikorska D, Scigacz A, Lindholm B, Pawlaczyk K, Oko A. Dialysis vintage stratified comparison of body composition, hydration and nutritional state in peritoneal dialysis and hemodialysis patients. Arch Med Sci. 2018; 14:807-817. https://doi.org/10.5114/aoms.2016.61902. [PubMed]

7. Abdallah E, El-Shishtawy S, Mosbah O, Zeidan M. Comparison between the effects of intraoperative human albumin and normal saline on early graft function in renal transplantation. Int Urol Nephrol. 2014; 46:2221-2226. https://doi.org/10.1007/s11255-014-0785-z. [PubMed]

8. Appenrodt B, Lammert F. Renal Failure in Patients with Liver Cirrhosis: Novel Classifications, Biomarkers, Treatment. Visc Med. 2018; 34:246-252. https://doi. org/10.1159/000492587. [PubMed]

9. Heimans L, van den Broek M, le Cessie S, Siegerink B, Riyazi N, Han KH, Kerstens PJ, Huizinga TW, Lems WF, Allaart CF. Association of high body mass index with decreased treatment response to combination therapy in recent-onset rheumatoid arthritis patients. Arthritis Care Res. 2013; 65:1235-1242. https://doi.org/10.1002/ acr.21978. [PubMed]

10. Morishita R, Franco MC, Suano-Souza FI, Solé D, Puccini RF, Strufaldi MW. Body mass index, adipokines and insulin resistance in asthmatic children and adolescents. J Asthma. 2016; 53:478-484. https://doi.org/10.3109/02770903.2015 1113544. [PubMed]

11. Lin YM, Wang M, Sun NX, Liu YY, Yin TF, Chen C. Screening and application of nutritional support in elderly hospitalized patients of a tertiary care hospital in China. PLoS One. 2019; 14:e0213076. https://doi.org/10.1371/ journal.pone.0213076. [PubMed]

12. Beattie AH, Prach AT, Baxter JP, Pennington CR. A randomised controlled trial evaluating the use of enteral nutritional supplements postoperatively in malnourished surgical patients. Gut. 2000; 46:813-818. https://doi. org/10.1136/gut.46.6.813. [PubMed]

13. Calderon C, Carmona-Bayonas A, Beato C, Ghanem I, Hernandez R, Majem M, Rosa Diaz A, Higuera O, Mut Lloret M, Jimenez-Fonseca P. Risk of malnutrition and emotional distress as factors affecting health-related quality of life in patients with resected cancer. Clin Transl Oncol. 2019; 21:687691. https://doi.org/10.1007/s12094-018-1954-9. [PubMed]

14. Hirahara N, Tajima Y, Fujii Y, Yamamoto T, Hyakudomi R, Taniura T, Kaji S, Kawabata Y. Preoperative Prognostic Nutritional Index Predicts Long-term Outcome in Gastric Cancer: A Propensity Score-matched Analysis. Anticancer Res. 2018; 38:4735-4746. https://doi.org/10.21873/ anticanres.12781. [PubMed]
15. Ikeguchi M, Urushibara S, Shimoda R, Yamamoto $M$, Maeta Y, Ashida K. Inflammation-based prognostic scores and nutritional prognostic index in patients with locallyadvanced unresectable colorectal cancer. World J Surg Oncol. 2014; 12:210. https://doi.org/10.1186/1477-781912-210. [PubMed]

16. Suzuki S, Kanaji S, Yamamoto M, Oshikiri T, Nakamura T, Kakeji Y. Controlling Nutritional Status (CONUT) Score Predicts Outcomes of Curative Resection for Gastric Cancer in the Elderly. World J Surg. 2019; 43:1076-1084. https:// doi.org/10.1007/s00268-018-04889-6. [PubMed]

17. Matsumura T, Mitani Y, Oki Y, Fujimoto Y, Ohira M, Kaneko H, Kawashima T, Nishio M, Ishikawa A. Comparison of Geriatric Nutritional Risk Index scores on physical performance among elderly patients with chronic obstructive pulmonary disease. Heart Lung. 2015; 44:534-538. https://doi.org/10.1016/j.hrtlng.2015.08.004. [PubMed]

18. Takahashi H, Ito Y, Ishii H, Aoyama T, Kamoi D, Kasuga H, Yasuda K, Maruyama S, Matsuo S, Murohara T, Yuzawa Y. Geriatric nutritional risk index accurately predicts cardiovascular mortality in incident hemodialysis patients. J Cardiol. 2014; 64:32-36. https://doi.org/10.1016/j. jijcc.2013.10.018. [PubMed]

19. Kinugasa Y, Kato M, Sugihara S, Hirai M, Yamada K, Yanagihara K, Yamamoto K. Geriatric nutritional risk index predicts functional dependency and mortality in patients with heart failure with preserved ejection fraction. Circ J. 2013; 77:705-711. https://doi.org/10.1253/circj.cj-12-1091. [PubMed]

20. Honda Y, Nagai T, Iwakami N, Sugano Y, Honda S, Okada A, Asaumi Y, Aiba T, Noguchi T, Kusano K, Ogawa H, Yasuda S, Anzai T; NaDEF investigators. Usefulness of Geriatric Nutritional Risk Index for Assessing Nutritional Status and Its Prognostic Impact in Patients Aged $\geq 65$ Years With Acute Heart Failure. Am J Cardiol. 2016; 118:550-555. https://doi.org/10.1016/j.amjcard.2016.05.045. [PubMed]

21. Hikage M, Tokunaga M, Makuuchi R, Irino T, Tanizawa Y, Bando E, Kawamura T, Terashima M. Reply to comment on "Are body mass index and performance status enough to assess the nutritional and functional status of elderly patients undergoing gastric cancer surgery?". Surg Today. 2018; 48:1102-1103. https://doi.org/10.1007/s00595-018-1702-3. [PubMed]

22. Lidoriki I, Schizas D. Are body mass index and performance status enough to assess the nutritional and functional status of elderly patients undergoing gastric cancer surgery? Surg Today. 2018; 48:1100-1101. https://doi.org/10.1007/ s00595-018-1685-0. [PubMed]

23. Takeda K, Umezawa R, Takahashi N, Matsushita H, Kozumi M, Ishikawa Y, Yamamoto T, Takeda K, Jingu $\mathrm{K}$. Impact of change in serum albumin level during and after chemoradiotherapy in patients with locally advanced esophageal cancer. Esophagus. 2018; 15:190-197. https:// doi.org/10.1007/s10388-018-0612-1. [ [PubMed] 
24. Sugino H, Hashimoto I, Tanaka Y, Ishida S, Abe Y, Nakanishi H. Relation between the serum albumin level and nutrition supply in patients with pressure ulcers: retrospective study in an acute care setting. J Med Invest. 2014; 61:15-21. https:// doi.org/10.2152/jmi.61.15. [PubMed]

25. Mansoor H, Zeb F. Enteral stents are safe and effective to relieve malignant gastric outlet obstruction in the elderly. J Gastrointest Cancer. 2015; 46:42-47. https://doi. org/10.1007/s12029-014-9675-y. [PubMed]

26. Roubenoff R. Molecular basis of inflammation: relationships between catabolic cytokines, hormones, energy balance, and muscle. JPEN J Parenter Enteral Nutr. 2008; 32:630-632. https://doi.org/10.1177/0148607108324875. [PubMed]

27. Moldawer LL, Copeland EM 3rd. Proinflammatory cytokines, nutritional support, and the cachexia syndrome: interactions and therapeutic options. Cancer. 1997; 79:1828-1839. https:// doi.org/10.1002/(SICI)1097-0142(19970501)79:9<1828::AIDCNCR28>3.0.CO;2-Z. [PubMed]

28. Ota A, Kondo N, Murayama N, Tanabe N, Shobugawa $\mathrm{Y}$, Kondo K, and Japan Gerontological Evaluation Study (JAGES) group. Serum Albumin Levels and Economic Status in Japanese Older Adults. PLoS One. 2016; 11:e0155022. https://doi.org/10.1371/journal. pone.0155022. [ [PubMed]

29. Sullivan DH, Johnson LE, Dennis RA, Roberson PK, Heif M, Garner KK, Bopp MM. The Interrelationships among albumin, nutrient intake, and inflammation in elderly recuperative care patients. J Nutr Health Aging. 2011; 15:311-315. https://doi.org/10.1007/s12603-010-0297-1. [PubMed]

30. Jeznach-Steinhagen A, Słotwiński R, Szczygieł B. Malnutrition, inflammation, atherosclerosis in hemodialysis patients. Rocz Panstw Zakl Hig. 2007; 58:83-88. [PubMed]

31. Melling N, Grüning A, Tachezy M, Nentwich M, Reeh M, Uzunoglu FG, Vashist YK, Izbicki JR, Bogoevski D.
Glasgow Prognostic Score may be a prognostic index for overall and perioperative survival in gastric cancer without perioperative treatment. Surgery. 2016; 159:1548-1556. https://doi.org/10.1016/j.surg.2016.01.018. [PubMed]

32. Yuan SQ, Nie RC, Chen YM, Qiu HB, Li XP, Chen XJ, Xu LP, Yang LF, Sun XW, Li YF, Zhou ZW, Chen S, Chen YB. Glasgow Prognostic Score is superior to ECOG PS as a prognostic factor in patients with gastric cancer with peritoneal seeding. Oncol Lett. 2018; 15:4193-4200. https://doi.org/10.3892/ol.2018.7826. [PubMed]

33. Takagi K, Domagala P, Polak WG, Buettner S, Wijnhoven BPL, Ijzermans JNM. Prognostic significance of the controlling nutritional status (CONUT) score in patients undergoing gastrectomy for gastric cancer: a systematic review and meta-analysis. BMC Surg. 2019; 19:129. https:// doi.org/10.1186/s12893-019-0593-6. [PubMed]

34. Khalfallah M, Jerraya H, Sbai A, Dougaz W, Changuel A, Nouira R, Bouasker I, Dziri C. Prognostic Nutritional Index score is useful to predict post-operative mortality and morbidity in gastric cancer. Tunis Med. 2016; 94:401-405. [PubMed]

35. Sun J, Wang D, Mei Y, Jin H, Zhu K, Liu X, Zhang Q, Yu J. Value of the prognostic nutritional index in advanced gastric cancer treated with preoperative chemotherapy. J Surg Res. 2017; 209:37-44. https://doi.org/10.1016/j.jss.2016.09.050. [PubMed]

36. Rosenberg I. Summary comments. Am J Clin Nutr. 1989; 50:1231-33. https://doi.org/10.1093/ajen/50.5.1231.

37. Clavien PA, Barkun J, de Oliveira ML, Vauthey JN, Dindo D, Schulick RD, de Santibanes E, Pekolj J, Slankamenac K, Bassi C, Graf R, Vonlanthen R, Padbury R, et al. The Clavien-Dindo classification of surgical complications: five-year experience. Ann Surg. 2009; 250:187-196. https:// doi.org/10.1097/SLA.0b013e3181b13ca2. [PubMed] 